\title{
Synthesis and Evaluation of Calcium-Deficient Hydroxyapatite with $\mathrm{SiO}_{2}$
}

\author{
Atsushi Nakahira ${ }^{1,2}$, Kentaro Nakata ${ }^{1}$, Chiya Numako ${ }^{3}$, Hidenobu Murata ${ }^{4}$, Katsuyuki Matsunaga ${ }^{4}$ \\ ${ }^{1}$ Osaka Prefecture University, Sakai, Japan; ${ }^{2}$ Osaka Center, IMR, Tohoku University, Sendai, Japan; ${ }^{3}$ The University of Tokushima, \\ Tokushima, Japan; ${ }^{4}$ Nagoya University, Chikusa-ku, Japan. \\ Email: nakahira@mtr.osakafu-u.ac.jp
}

Received May $23^{\text {rd }}, 2011$; revised June $2^{\text {nd }}, 2011$; accepted June $9^{\text {th }}, 2011$.

\begin{abstract}
Effect of $\mathrm{SiO}_{2}$ addition on the microstructures of calcium-deficient hydroxyapatite prepared by the heat-treatments was examined. Obtained hydroxyapatites substituted with Si ion were characterized by XRD, FT-IR and XAFS measurements. XANES results of Si K-edge and P K-edge in these modified hydroxyapatites indicated the shift of peaks of $P$ $K$-edge with the $\mathrm{SiO}_{2}$ contents, although no change of Si local structures. In this study, the effect of Si ion on micro-and local structure of hydroxyapatite with $\mathrm{SiO}_{2}$ addition was mainly clarified.
\end{abstract}

Keywords: Hydroxyapatite, $\mathrm{SiO}_{2}, \mathrm{XAFS}$, Local Structure

\section{Introduction}

It is well-known that hydroxyapatite (HAP) is a major inorganic component of bone and teeth. Since HAP possesses high bioactivity, osteoconductivity and bio-compatibility, it is extremely useful as a biomaterial for artificial implant parts, bone fillers, and bone-cements etc. [1-6].

On the contrary, HAP has also both the high ability of ion exchange against cations and anions and adsorbent for various amino acids and proteins among other inorganic materials [5-10]. In bone, HAP is usually calciumdeficient below $\mathrm{Ca} / \mathrm{P}$ of 1.67 , not stoichiometry " $\left(\mathrm{Ca}_{10}\left(\mathrm{PO}_{4}\right)_{6}(\mathrm{OH})_{2}\right)$ with $\mathrm{Ca} / \mathrm{P}$ of 1.67 ", for the achievement of doping metal ions and control of the solubility. As a consequence, nonstoichiomeric HAP with $\mathrm{Ca} / \mathrm{P}$ of less than 1.67 possesses the high ion-exchange ability of various cations. Therefore, calcium-deficient HAP is expected to be applicable as an ion-exchange media for solving environmental problems, such as the purification for water and soil polluted with heavy metals as well as biomedical applications [10,11]. Recently, the syntheses of HAP doped with functional elements ( $\mathrm{Zn}$ and $\mathrm{Fe}$ ) are also attempted for developing high performance bioceramics for biomedical application and the clarification of effects of functional elements on the properties and microstructures is carried out in order to develop the high performance bioceramics.
The syntheses of HAP substituted with other metals have been eagerly attempted by various synthetic processes, such as hydrothermal treatments, ion-exchange treatments, and normal heat-treatments at high temperature in order to enhance the ion exchange ability and bioactivity of HAP [9-15]. For example, Fe substituted HAP i.e. abbreviated by "HAP modified with Fe ions", synthesized by hydrothermal treatment indicated the good exchange ability against $\mathrm{As}$ and $\mathrm{Pb}$ etc., compared to monolithic HAP. However, in fact, monolithic HAP doped with metal ions is significantly difficult to synthesize without any other phase.

Since Bonefield reported that HAP containing with $\mathrm{SiO}_{2}$ indicated high bioactivity and osteoconductivity [14], the synthesis of HAP with $\mathrm{SiO}_{2}$ and tricalcium phosphate (TCP) with $\mathrm{SiO}_{2}$ have been performed by many researchers. However, HAP with $\mathrm{SiO}_{2}$ addition often results in the formation of reaction phase between $\mathrm{HAP}$ and $\mathrm{SiO}_{2}$, such as calcium silicate, and phosphate glass etc, and unreacted $\mathrm{SiO}_{2}$ residue. Thus, the $\mathrm{SiO}_{2}$ doped $\mathrm{HAP}$ without reaction phases and $\mathrm{SiO}_{2}$ residue is difficult to synthesize by the conventional methods. However, the successful synthesis of $\mathrm{SiO}_{2}$ doped HAP will lead to understanding effect of $\mathrm{SiO}_{2}$ element on the high bioactivity and osteoconductivity for $\mathrm{SiO}_{2}$ doped HAP.

In this study, the main purpose is to synthesize $\mathrm{SiO}_{2}$ doped HAP. As a strategy, the incorporation of Si ions 
into HAP was especially carried out by using whiskerlike calcium-deficient HAP as a starting material, not stoichiometric HAP. Whisker-like calcium-deficient HAP powders were synthesized by the soft chemical processing for the hydrolysis of $\alpha$-TCP. In addition, calciumdeficient HAP containing $\mathrm{SiO}_{2}$ was normally heat-treated in air atmosphere and the effect of $\mathrm{SiO}_{2}$ addition on micro- and local structure of HAP was examined. Furthermore, Si and P local structures of these substituted HAP were investigated by the XANES.

\section{Experimental Procedures}

\subsection{Synthesis}

HAP powder was synthesized by the soft chemical processing for the hydrolysis of $\alpha$-TCP [15]. $10 \mathrm{~g}$ of $\alpha$-TCP powder was stirred in $200 \mathrm{ml}$ of 1-octanol at $70^{\circ} \mathrm{C}$ for 48 $\mathrm{h}$. The solution during reaction was kept at $\mathrm{pH} 11$ with $0.1 \mathrm{M} \mathrm{NH}_{4} \mathrm{OH}$. The precipitation was filtered with the membrane and washed with ethanol and ion-exchange water sufficiently and then dried at $50^{\circ} \mathrm{C}$ for $24 \mathrm{~h}$. Commercial $\mathrm{SiO}_{2}$ powder from Tokuyama Chemical (Tokushiru) was used as a source of $\mathrm{Si}$ ion. $\mathrm{SiO}_{2}(3,10$, and 30 $w t \%)$ was added into HAP powder and mixed in ethanol with ball milling for $24 \mathrm{~h}$. After mixing, the mixture was filtered with membrane and subsequently dried at $323 \mathrm{~K}$. The dried powder was crashed with alumina mortal. Mixed $\mathrm{HAP} / \mathrm{SiO}_{2}$ powder was compacted with stainless mold. Dimension of pellets was $2 \mathrm{~mm}$ in thickness and $20 \mathrm{~mm}$ in diameter. Pellets were heated at $600^{\circ} \mathrm{C}$ to $1200^{\circ} \mathrm{C}$ in air atmosphere. Heating rate was $5^{\circ} \mathrm{C} / \mathrm{min}$. After holding at the high temperature for $2 \mathrm{~h}$, samples were cooled in furnace. Heat-treated samples were polished with diamond paste.

\subsection{Evaluations}

The component of samples was identified with XRD (Rint-2000: Rigaku, Tokyo, Japan). The microstructure of samples was observed by SEM (S-450: Hitachi, Tokyo, Japan) and TEM (FX-2010: JOEL, Tokyo, Japan). The samples were evaluated with FT-IR equipment (Shimazu, Tokyo, Japan). Si-K and P-K edge were measured at UVSOR in Okazaki.

\section{Results and Discussion}

Figure 1 shows XRD and SEM results of HAP samples synthesized by the soft chemical processing, i.e. the hydrolysis of $\alpha$-TCP in 1-octanol at $70^{\circ} \mathrm{C}$ for $48 \mathrm{~h}$. XRD results indicated that products were composed of monolithic HAP and no other phase like calcium phosphate. From SEM observation, HAP particles synthesized by the hydrolysis of $\alpha$-TCP were observed to be whiskerlike. From ICP measurements, $\mathrm{Ca} / \mathrm{P}$ ratio of calcium-

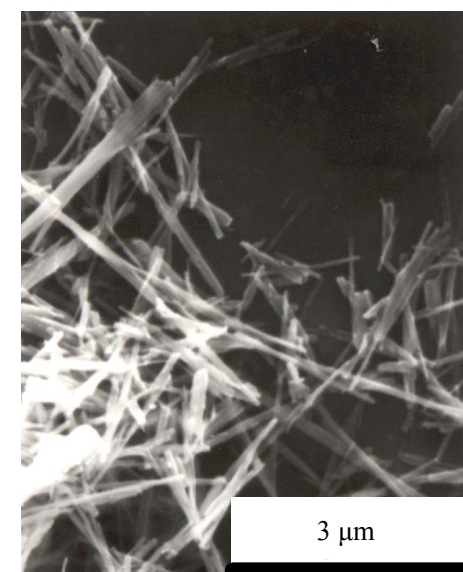

(a)

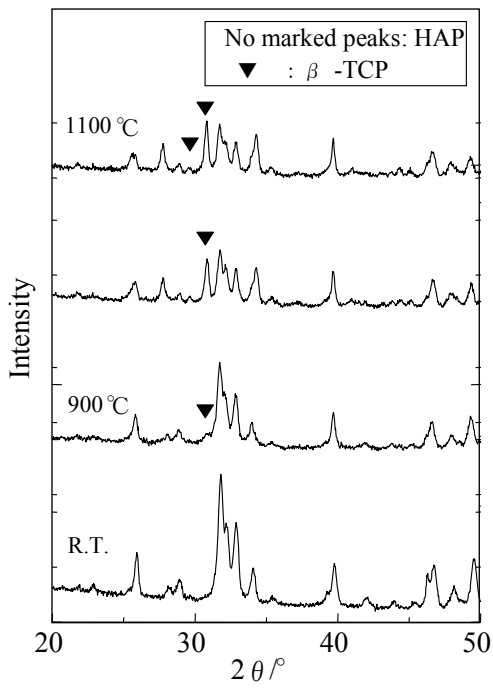

(b)

Figure 1. (a) XRD and (b) SEM image of whisker Ca-deficient HAP synthesized by the hydrolysis of $\alpha$-TCP in 1octanol at $70^{\circ} \mathrm{C}$ for $48 \mathrm{~h}$.

deficient $\mathrm{HAP}$ added with $\mathrm{SiO}_{2}(0 \mathrm{wt} \%, 3 \mathrm{wt} \%, 30 \mathrm{wt} \%)$ were evaluated for samples synthesized by the soft chemical processing. ICP results indicated that this whiskerlike HAp had 1.580 of $\mathrm{Ca} / \mathrm{P}$ ratio, suggesting that obtained whisker-like HAP was calcium-deficient. On the other hand, $\mathrm{Ca} / \mathrm{P}$ ratio of calcium-deficient $\mathrm{HAP}$ added with $3 \mathrm{wt} \% \mathrm{SiO}_{2}$ and $30 \mathrm{wt} \%$ were 1.590 and 1.603 , respectively. It was obvious that the addition of $\mathrm{SiO}_{2}$ into calcium-deficient HAP samples resulted in the decrease of $\mathrm{Ca} / \mathrm{P}$ ratio.

XRD results of calcium-deficient HAP samples containing 3 to $30 \mathrm{wt} \% \mathrm{SiO}_{2}$ heat-treated at $600^{\circ} \mathrm{C}$ to $1200^{\circ} \mathrm{C}$ are shown in Figure 2. HAP samples without $\mathrm{SiO}_{2}$ heattreated at $600^{\circ} \mathrm{C}$ were composed of HAP phase without another calcium phosphate phase, although HAP samples heat-treated at $1000^{\circ} \mathrm{C}$ have the mixture of HAP and 

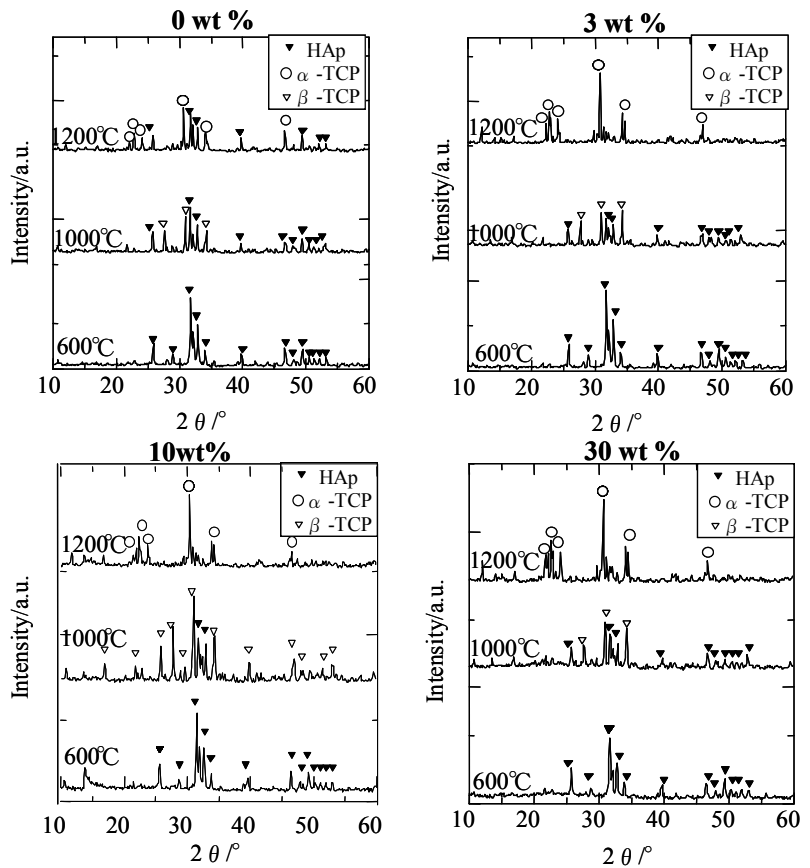

Figure 2. XRD results of Ca-def $\mathrm{HAp}$ added with $\mathrm{SiO}_{2}(0$ wt $\%, 3 \mathrm{wt} \%, 10 \mathrm{wt} \%$, and $30 \mathrm{wt} \%$ ) heat-treated at various temperatures.

$\alpha$-TCP. The component of samples heat-treated at $1200^{\circ} \mathrm{C}$ was the mixture of HAP and $\alpha$-TCP. In case of HAP/ $3 \% \mathrm{SiO}_{2}$, samples heat-treated at $600^{\circ} \mathrm{C}$ contained HAP monophase. $\mathrm{HAP} / 3 \% \mathrm{SiO}_{2}$ samples heat-treated at $1200^{\circ} \mathrm{C}$ were composed of mainly $\alpha$-TCP and in part HAP, although the component of samples heat-treated at $1000^{\circ} \mathrm{C}$ were $\mathrm{HAP}$ and $\alpha$-TCP. $\mathrm{HAP} / 10 \% \mathrm{SiO}_{2}$ and $\mathrm{HAP} / 30 \%$ $\mathrm{SiO}_{2}$ samples indicated the same dependence of heattreatment temperatures for XRD results. For HAP $/ 10 \%$ $\mathrm{SiO}_{2}$ and $\mathrm{HAP} / 30 \% \mathrm{SiO}_{2}$, samples heat-treated at $600^{\circ} \mathrm{C}$ were composed of monolithic HAP and ones at $1200^{\circ} \mathrm{C}$ were of $\alpha$-TCP, respectively. On the other hand, both $\mathrm{HAP} / 10 \% \mathrm{SiO}_{2}$ and $\mathrm{HAP} / 30 \% \mathrm{SiO}_{2}$ samples heat-treated at $1000^{\circ} \mathrm{C}$ were composed of HAP and $\alpha$-TCP. Thus, it was found that the addition of $\mathrm{SiO}_{2}$ into calcium-deficient HAP enhanced the formation of $\alpha$-TCP above $1000^{\circ} \mathrm{C}$.

Figure 3 shows the variation of FT-IR spectra of calcium-deficient $\mathrm{HAP} / \mathrm{SiO}_{2}$ samples heat-treated at $600^{\circ} \mathrm{C}$ with $\mathrm{SiO}_{2}$ content. $\mathrm{HAP} / \mathrm{SiO}_{2}$ samples with higher $\mathrm{SiO}_{2}$ content indicated the stronger peak from $\mathrm{SiO}_{4}^{4-}$ with $\mathrm{SiO}_{2}$ content. However, as obviously shown in figure, the peak form phosphate $\left(\mathrm{PO}_{4}^{3-}\right)$ for $\mathrm{HAP} / \mathrm{SiO}_{2}$ samples decreased with increase of $\mathrm{SiO}_{2}$ content. In addition, the peak from $\mathrm{OH}^{-}$for $\mathrm{HAP} / \mathrm{SiO}_{2}$ samples decreased with high $\mathrm{SiO}_{2}$ content of $30 \%$. In this study, XRD results indicated no formation of calcium silicate for $\mathrm{HAP} / \mathrm{SiO}_{2}$ samples heat-treated at $600^{\circ} \mathrm{C}$. These FT-IR results, in conjunction with XRD and FT-IR results, indicate that

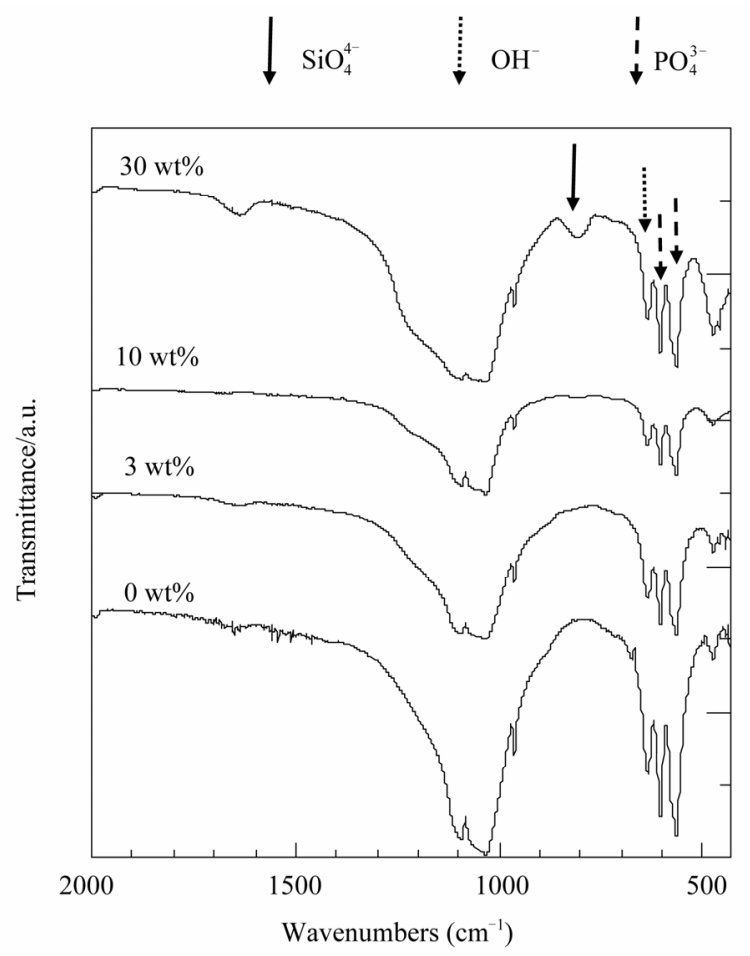

Figure 3. FT-IR results of Ca-def $\mathrm{HAp}$ added with $\mathrm{SiO}_{2}(0$ $w t \%, 3 w t \%, 10 w t \%$, and $30 \mathrm{wt} \%$ ) heat-treated at $600{ }^{\circ} \mathrm{C}$.

$\mathrm{SiO}_{2}$ was incorporated into calcium-deficient HAP structures, although the excess addition of $\mathrm{SiO}_{2}$ (e.g. $30 \mathrm{wt} \%$ addition) and heat treatment at high temperatures have the possibility of formation of calcium silicate. Therefore, these results indicate that $\mathrm{SiO}_{4}^{4-}$, below the optimum $\mathrm{SiO}_{2}$ contents, was substituted for $\mathrm{PO}_{4}^{3-}$ site in calciumdeficient HAP structure during the heat-treatment at $600^{\circ} \mathrm{C}$.

The microstructures of these calcium-deficient $\mathrm{HAP} / 3$ $\sim 10 \mathrm{wt} \% \mathrm{SiO}_{2}$ heat-treated at $600^{\circ} \mathrm{C}$ were observed with SEM. Figure 4 shows SEM images of calcium-deficient HAP samples containing 0,3 and $10 \mathrm{wt} \% \mathrm{SiO}_{2}$ after the heat-treatment at $600^{\circ} \mathrm{C}$. Although calcium-deficient HAP/ $3 \sim 10 \mathrm{wt} \% \mathrm{SiO}_{2}$ were whisker-like as well as calciumdeficient HAP samples without $\mathrm{SiO}_{2}$, the length of whisker-like products decreased with $\mathrm{SiO}_{2}$ content. Also, no agglomerate and grain growth of HAP grains were confirmed after heat-treatment at $600^{\circ} \mathrm{C}$. Thus, the addition of $\mathrm{SiO}_{2}$ into calcium-deficient HAP resulted in the inhibition of HAP grain growth, which was caused by the substitution of $\mathrm{SiO}_{4}^{4-}$ for $\mathrm{PO}_{4}^{3-}$ site in hydroxyapatite structure during the heat-treatment.

Figures 5 and $\mathbf{6}$ shows the spectra of XANES of P $K$-edge and Si $K$-edge for calcium-deficient HAP $/ 3 \sim 10$ wt $\% \mathrm{SiO}_{2}$ heat-treated at $600^{\circ} \mathrm{C}$, compared to monolithic $\mathrm{HAP}$ and samples heat-treated at $600^{\circ} \mathrm{C}$ and quartz as a reference material. From measurement in Si $K$-edge, 

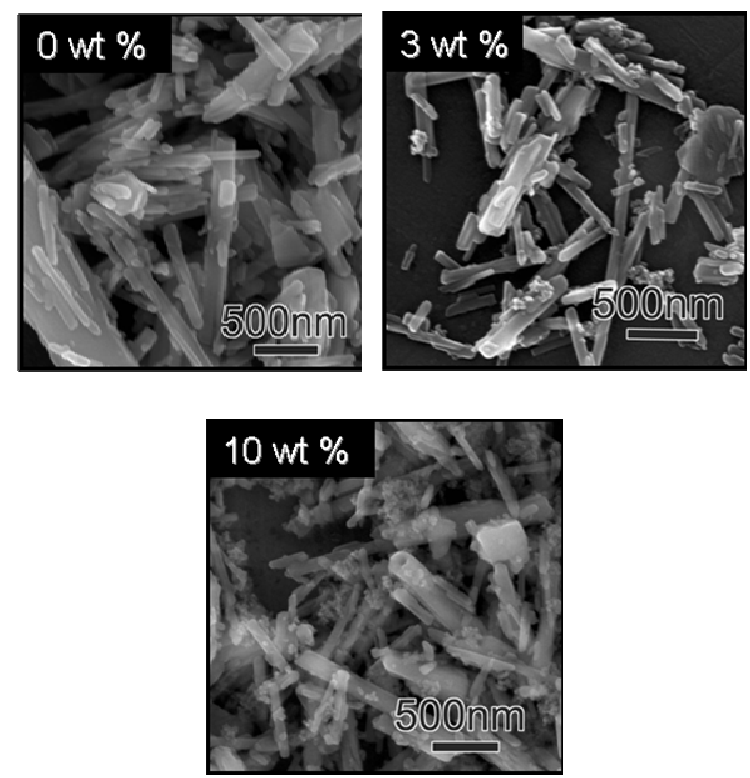

Figure 4. SEM images of calcium-deficient HAP samples containing 0,3 and $10 \mathrm{wt} \% \mathrm{SiO}_{2}$ after the heat-treatment at $600^{\circ} \mathrm{C}$.

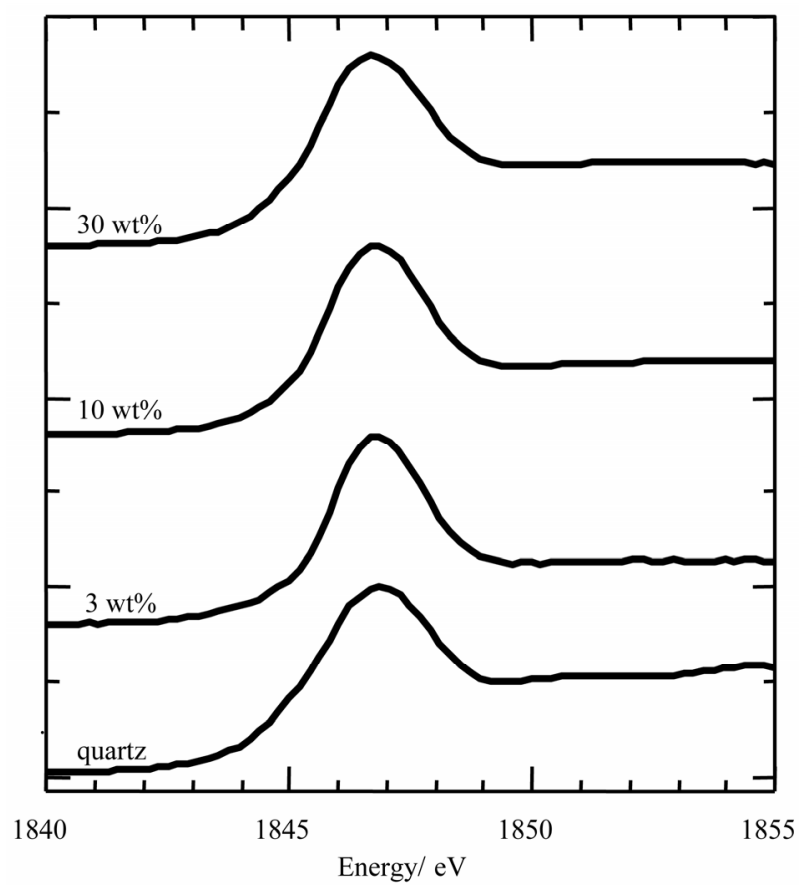

Figure 5. Results of Si K-edge XANES spectra of calciumdeficient $\mathrm{HAP} / 0 \sim 30 \mathrm{wt} \% \mathrm{SiO}_{2}$ heat treated at $600^{\circ} \mathrm{C}$.

Si-local structures of calcium-deficient HAP/3 $10 \mathrm{wt} \%$ $\mathrm{SiO}_{2}$ heat-treated at $600^{\circ} \mathrm{C}$ was the same as the quartz and had no peak shifts, as shown in Figures 5. However, in case of $\mathrm{P}$ local structures, the peak of $\mathrm{P} K$-edge was shifted to higher energy with the $\mathrm{SiO}_{2}$ contents. This result indicated that local structure around $\mathrm{P} K$-edge for

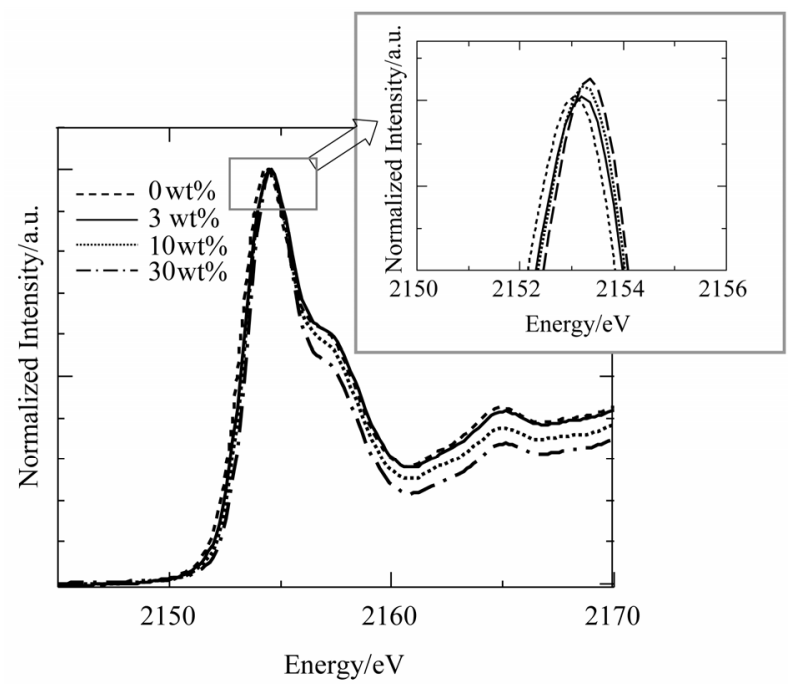

Figure 6. Results of $P$ K-edge XANES spectra of calciumdeficient $\mathrm{HAP} / 0 \sim 30 \mathrm{wt} \% \mathrm{SiO}_{2}$ heat-treated at $600^{\circ} \mathrm{C}$.

calcium-deficient $\mathrm{HAP} / 3 \mathrm{wt} \% \mathrm{SiO}_{2}$ heat-treated at $600^{\circ} \mathrm{C}$ was slightly different from monolithic HAP and HAP with a large amount of $\mathrm{SiO}_{2}$. On the contrary, calciumdeficient $\mathrm{HAP} / 10 \sim 30 \mathrm{wt} \% \mathrm{SiO}_{2}$ heat-treated at $600^{\circ} \mathrm{C}$ had the significantly different local structure around $\mathrm{P}$ $K$-edge compared to monolithic HAP and HAP/3 $\mathrm{wt} \%$ $\mathrm{SiO}_{2}$. These XANES, XRD and FT-IR results also suggest that $\mathrm{SiO}_{4}^{4-}$ was substituted for $\mathrm{PO}_{4}^{3-}$ in hydroxyapatite structure. The difference in XANES spectra between $\mathrm{HAP} / 3$ wt $\% \quad \mathrm{SiO}_{2}$ samples and others are thought to be caused by the electron state. According to results reported by Harris et al. [16], the substitution of $\mathrm{PO}_{4}^{3-}$ site by carbonate ( 2 to $6 \mathrm{wt} \%$ ) produced marked change in EXAFS (extended X-ray absorption fine structure), leading to the structural distortion in hydroxyapatite structure due to the incorporation of carbonate into hydroxyapatite. This phenomenon and furthermore the theoretical defect energetics in hydroxyapatite is under investigation. Thus, these results indicated the noticeable structural changes accompany the substitution of $\mathrm{SiO}_{4}^{4-}$ into $\mathrm{PO}_{4}^{3-}$ site in hydroxyapatite structure.

\section{Conclusions}

Effect of $\mathrm{SiO}_{2}$ addition on the microstructures of calcium-deficient HAP prepared by the soft chemical processing was investigated. HAP substituted with Si ion was synthesized by the normal heat-treatment at $600^{\circ} \mathrm{C}$ to $1200^{\circ} \mathrm{C}$ for $2 \mathrm{~h}$ in air atmosphere. The results of FT-IR measurements for modified HAP indicated that the peak from $\mathrm{PO}_{4}^{3-}$ decreased with the $\mathrm{SiO}_{2}$ contents. Microstructural observations indicated that the incorporation of $\mathrm{SiO}_{2}$ inhibited the growth of HAP grain. Evaluation of $\mathrm{P}$ 
$K$-edge indicated the XANES spectra of HAP/10 $~ 30$ wt $\% \mathrm{SiO}_{2}$ heat-treated at $600^{\circ} \mathrm{C}$ were different from that of monolithic $\mathrm{HAP}$ and $\mathrm{HAP} / 3 \mathrm{wt} \% \mathrm{SiO}_{2}$ samples. These results of micro- and local structure of modified HAP suggest that $\mathrm{SiO}_{4}^{4-}$ was substituted for $\mathrm{PO}_{4}^{3-}$ in hydroxyapatite structure.

\section{Acknowledgements}

We thank UVSOR for the support of XAFS measurement at BL1A in UVSOR. This work was partly supported by Grant-in Aid for Scientific Research on Primary Area "Nano-materials Science for Atomic Scale Modification (area No. 474)".

\section{REFERENCES}

[1] E. O. Martz, V. K. Goel, M. H. Pope and J. B. Park, "Materials and Design of Spinal Implants," Journal of Biomedical Materials Research, Vol. 38, No. 3, 1997, pp. 267-288.

doi:10.1002/(SICI)1097-4636(199723)38:3<267::AID-JB $\mathrm{M} 12>3.0 . \mathrm{CO} ; 2-8$

[2] F. B. Bagambisa, U. Joos and W. Schilli, "Mechanisms and Structure of the Bond between Bone and Hydroxyapatite Ceramics," Journal of Biomedical Materials Research, Vol. 27, No. 8, 1993, pp. 1047-1055. doi: $10.1002 / \mathrm{jbm} .820270810$

[3] M. Okazaki, "Specific Physicochemical Properties of Apatite and Their Application to Biomaterials," Phosphorous Research Bulletin, Vol. 20, 2006, pp. 25-32.

[4] A. Almirall, G. Larrecq, J. A. Delgado, S. Martinez, J. A. Planell and M. P. Ginebra, "Fabrication of Low Temperature Macroporous Hydroxyapatite Scaffolds by Foaming and Hydrolysis of an $\alpha$-TCP Paste," Biomaterials, Vol. 25, No. 17, 2004, pp. 3671-3680.

[5] M. Tamai, T. Isshiki, K. Nishio, M. Nakamura, A. Nakahira and H. Endoh, "A Metastable Phase in Thermal Decomposition of Ca-Deficient Hydroxyapatite," Journal of Materials Science: Materials in Medicine, Vol. 14, No. 7, 2003, pp. 617-622. doi:10.1023/A:1024075008165

[6] E. S. Ahn, N. J. Gleason, A. Nakahira and J. Y. Ying, "Nanostructure Processing of Hydroxyapatite-Based Bioceramics," Nano Letters, Vol. 1, No. 3, 2001, pp. 149-153. doi:10.1021/n10055299

[7] A. Nakahira, S. Aoki, K. Sakamoto and S. Yamaguchi, "Synthesis and Evaluation of Various Layered Octacalcium Phosphate by Wet-Chemical Processing," Journal of Materials Science: Materials in Medicine, Vol. 12, No. 9, 2001, pp. 793-800.

[8] S. Aoki, S. Yamaguchi, A. Nakahira and K. Suganuma, "A New Approach to an Artificial Joint Based on BioCartilage/Porous $\alpha$-Tricalcium Phosphate System," Journal of the European Ceramic Society, Vol. 23, No. 15, 2003, pp. 2939-2946.

[9] H.-J. Kleebe, A. Nakahira and G. Pezzotti, "Microstructure and Microcrack Formation at Grain Boundaries in $\mathrm{Na}_{3} \mathrm{PO}_{4}$-Doped Hydroxyapatite," Journal of the Ceramic Society of Japan, Vol. 109, No. 1267, 2001, pp. 181-185. doi:10.2109/jcersj.109.1267_181

[10] A. Nakahira, C. Karatani and S. Nishida, "Evaluation of Cadmium Removal in Solution Using Various Hydroxyapatite and Cattle Bone," Phosphorus Research Bulletin, Vol. 17, 2004, pp. 148-152.

[11] A. Nakahira, T. Okajima, T. Honma, S. Yoshioka and I. Tanaka, "Arsenic Removal by Hydroxyapatite-Based Ceramics," Chemistry Letters, Vol. 35, No. 8, 2006, pp. 856857. doi:10.1246/cl.2006.856

[12] A. Nakahira, S. Nakamura and M. Horimoto, "Synthesis of Modified Hydroxyapatite(HAP) Substituted with Fe Ion for DDS Application," IEEE Transactions on Magnetics, Vol. 43, No. 6, 2007, pp. 2465-2467. doi:10.1109/TMAG.2007.894358

[13] A. Nakahira, M. Horimoto, S. Nakamura, S. Ihshihara, H. Nagata, T. Kubo and C. Karatani, "Synthesis and Evaluation of High Performance Modified Hydroxyapatite," Journal of Ion Exchange, Vol. 18, 2007, pp. 306-309.

[14] I. R. Gibson, S. M. Best and W. Bonefield, "Chemical Characterization of Silicon-Substituted Hydroxyapatite," Journal of Biomedical Materials Research, Vol. 44, No. 4, 1999 , pp. 422-428. doi:10.1002/(SICI)1097-4636(19990315)44:4<422::AIDJBM8>3.0.CO;2-\#

[15] A. Nakahira, K. Sakamoto, S. Yamaguchi, M. Kaneno, S. Takeda and M. Okazaki, "Novel Synthesis Method of Hydroxyapatite Whiskers by Hydrolysis of Alpha-Tricalcium Phosphate in Mixtures of $\mathrm{H}_{2} \mathrm{O}$ and Organic Solvent," Journal of the American Ceramic Society, Vol. 82, No. 8, 1999, pp. 2029-2032. doi:10.1111/j.1151-2916.1999.tb02035.x

[16] J. E. Harries, D. W. L. Hukins, C. Holt and S. S. Hasnain, "Conversion of Amorphous Calcium Phosphate into Hydroxyapatite Investigated by EXAFS Spectroscopy," Journal of Crystal Growth, Vol. 84, No. 4, 1987, pp. 563-570. doi:10.1016/0022-0248(87)90046-7 